Ballestero, A. (2014). What Is in a Percentage?: Calculation as the Poetic Translation of Human Rights. Indiana Journal of Global Legal Studies, 21(1), 27-53.

\title{
What is in a Percentage?: Calculation as the Poetic Translation of Human Rights
}

\author{
Andrea Ballestero, Rice University [ORCID: 0000-0001-7692-0514]
}

\begin{abstract}
Increasingly, the efficacy of human rights, international norms, and commercial standards is deposited in numbers as measures of social and financial value. Taking the form of indicators, goals, and targets, these numbers are active participants in the everyday practices through which the law is constituted around the world. This paper examines the normative ability of percentages as numeric devices that transform measures of value across legal domains. The paper draws on two examples: a) the generation of indicators by NGOs promoting the Human Right to Water, and b) the technical work of regulators attempting to regulate water prices to follow the $3 \%$ affordability target that the United Nations advocates for. I argue that the process of translating human rights into numbers bestows rights with an afterlife that expands their reach into new domains. I also suggest that such process of translation is poetic and that exploring numbers and their role in lawmaking from a poetic point of view reveals the rich social lives that numbers lead. Attending more carefully to these numbers also shows the political [End Page 27] possibilities that translation processes across genres of communication afford a philosophy of human rights preoccupied not only with their violation, but also with their implementation.
\end{abstract}




\section{Introduction}

Since 2005, a myriad of institutions and organizations have been creating momentum for the recognition of the human right to water through a wide array of activities framed under the United Nations International Decade of Water for Life (2005-2015) programs. In part thanks to the attention that the international decade garnered, the United Nations Human Rights Council appointed Catharina de Albuquerque in 2008 as a special and independent rapporteur with the mandate of clarifying the scope of the human right to water. Her work was framed as an effort to clarify the necessary steps by which states could guarantee the broad enjoyment of this right. Rather than limiting her work to documenting violations of rights, following what we could broadly call a negative philosophy of rights, the rapporteur was asked to delineate a route for universal implementation, something we could gloss as a positive philosophy of rights. The rapporteur had the task of identifying paths to secure for everyone sufficient, safe, acceptable, physically accessible, and affordable water for personal and domestic uses, ${ }^{1}$ as the human right to water was defined.

Concretized in a series of programs, this positive philosophy was translated into a struggle to establish appropriate benchmarks, goals, and objectives to ensure that people everywhere could enjoy basic water and sanitation services and infrastructures. In discussing her 2011 General Assembly Report, de Albuquerque reflected on the difficulties that governments face in securing the human right to water and asserted, somewhat surprisingly, that, rather than increased financial resources, what was necessary for attaining global goals was "better-targeted interventions aligned with human rights obligations."2 Better targets, not necessarily more money, would allow countries and international agencies to reach their goals of water and sanitation for all. De Alburquerque's pronouncement repeated what has become a taken-forgranted argumentative structure of most calls for the human right to water and many other humanitarian interventions. That structure consists of a list of figures depicting the gravity of existing [End Page 28] water inequities around the world and a call to action justified on the basis of the dire picture the figures convey. De Alburquerque and many other technocrats, international bureaucrats, and activists trust that this combination of numeric figures and moral calls to action yield the "better targets" needed to turn positive philosophies of rights into concrete actions in the world.

In this concern for better targets, numbers are leading players that perform a dual function. On the one hand, they delineate a terrain for humanitarian intervention that mobilizes people's moral sentiments and galvanizes subsequent commitments. On the other hand, they measure those commitments in the form of goals, objectives, and indicators. Here we find numbers both as the basis of calls for action and also as better targets to affirm the positive philosophy of rights. I am interested in how exactly numbers perform this dual function and mobilize people's legal and political commitments in the human rights arena. Moreover, what does a specific type of number, the percentage, do to construct "better targeted" human rights interventions from the perspective of nongovernmental organizations (NGOs) and regulatory agencies? This paper presents a two-pronged argument to address these issues. First, I suggest that percentages determine better targets because they translate succinct definitions of human rights into complex webs of signification, responsibility, and economic redistribution outside of human rights courts and institutions. Second, and consequently, I suggest - against common wisdom - that 
percentages can perform that translation work because the better target is not the target that is concrete, narrow, and precise. To the contrary, these cases show that the better target, the target people engage with in their everyday lives, is the target that reinvents the meaning of human rights by expanding their original scope. In the hands of activists, lawyers, economists, and other experts that I introduce through two examples, I show how defining better targets entails the translation of a legal construct into a quantified genre of communication and how that translation is not mechanic but poetic.

In what follows I use two examples to illustrate how a ubiquitous tool, the numeric percentage, performs these expansive and poetic translations. The first example highlights how percentages communicate unconventional notions of self that focus on a shared responsibility to increase collective skills amongst NGOs working to promote the human right to water in Costa Rica. The second example reviews how economic regulators implement the United Nations Development Program (UNDP) guideline, which states that water [End Page 29] expenses should account for less than $3 \%$ of a household's income. ${ }^{3}$ Here, the percentage translates the part-whole relation between the person and the collective that is so central to liberalism. Together, these examples underline how human rights targets, in the form of percentages, enlarge the scope of human rights to include actors, institutions, and ideas that do not figure in analyses that center on human rights violations. More broadly, I show how the poetic translation that numbers perform endows human rights regulations with productive and assertive lives in unexpected locales. Those lives proliferate as they enact a positive philosophy of rights implementation.

While numbers and quantification have historically been central to human rights agendas, only recently have scholars turned their attention to the relations between the law and calculative practices. Most saliently, work that examines the use of indicators in the promotion and implementation of human rights has opened important areas of research. Scholars have highlighted the politics of numeration and the maneuvers that systems of indicators allow for in the unequal worlds of human rights, transnational regulations, and policy more broadly. ${ }^{4}$ Those contributions have opened important areas for further investigation. Yet, while these works have focused on the politics of number making across institutions, organizations, and even nations, they have paid less attention to the technical differences between types of numbers. For instance, they do not distinguish between the semiotic peculiarities of an integer in comparison with a percentage, to mention just one difference that, at first sight, might seem inconsequential for socio-legal scholars.

To avoid overlooking what might initially seem inconsequential but can have powerful effects, I follow Isabelle Stengers' call to "slow down reasoning and create an opportunity to arouse a slightly different awareness of the problems ... mobilizing us." ${ }^{, 5}$ Percentages are ubiquitous in diagnosing problems and devising solutions. In the case of human rights, percentages help establish systems of responsibility, economic relations, and future aspirations without explicit and constant recourse to the discursive legitimacy, or lack thereof, of the law. These [End Page 30] numeric devices have the capacity to index both the history and the future of a situation. When one claims, for instance, that about $90 \%$ of Costa Rican households have access to improved sources of water, one is simultaneously enveloping a past problem, in which the percentage was smaller, and a desired future, in which the percentage will reach $100 \%$. When de Albuquerque claims that, at any time, almost $50 \%$ of all people in developing countries are 
suffering from water related diseases, ${ }^{6}$ she is making a moral call to produce a future where that percentage would be, ideally, reduced to zero. This impetus for change is not without broader systems of legal control and ethical practice, yet, percentages have the capacity to reflect those broader systems and insert them into a form of signification for which transformation is inherent. Percentages are tied to their own change. When used to produce better targets, percentages bring with them this complex relation to temporality, the fluidity of social life, and collective ethical projects. This semiotic capacity of percentages offers human rights projects a dynamism that is sometimes difficult to map. Theorizations of translation offer a way to grasp that dynamism and the historical and semiotic changes that percentages precipitate. Before delving into the two examples this paper presents, I offer a brief and-by necessity-nonexhaustive review of translation as it has been analyzed by some key figures in social theory. Against this background, I then theorize translation through numbers as a shift in genres of communication with important material and political consequences. I then present the two examples before concluding with the question of what kind of translation labor percentages perform.

\section{Translation as a critical intellectual tradition}

Socio-legal scholarship has increasingly focused on a wide range of translation processes. Scholars are currently asking what exactly occurs when the law is "translated" across national boundaries, ${ }^{7}$ legal and administrative systems, ${ }^{8}$ languages, ${ }^{9}$ and religious and ethical [End Page 31] traditions. ${ }^{10}$ As the works of these scholars highlight, there is a diversity of social processes that are glossed as translation, and one is left with the question of what exactly is meant by translation and how expansive the concept might become if used for analytic purposes. ${ }^{11}$ Is there something that can be called a process of translation that provides any analytic traction beyond the colloquial uses of the term? My purpose here is not to develop a unifying understanding of translation since that would not only be a major theoretical project but also, to some extent, an intrinsically incomplete one. Instead, I will be as explicit as possible about the notion of translation that I am working with and about what kind of value I think we can get from this concept in the analysis of socio-legal life. ${ }^{12}$

Traditionally, and colloquially perhaps, translation has been understood as a process for creating equivalences across difference. ${ }^{13}$ It is often pictured as the movement of an expression or textual object from one language to another, with the expectation that, through such movement, the original object will be kept as intact as possible, albeit its new expression being in a new language, and consequently, placed in a new context. Here, translation is mostly about the preservation of meaning in the face of difference, in the face of a change of medium or context. This pretension of seamless continuity is, however, forever "haunted by its inevitable failure" given that a translated object is constantly measured against an original from which it derives its identity and to which it can never be identical. ${ }^{14}$ Translated objects [End Page 32] often carry a perennial mark of foreignness and, by extension, are always seen as potentially inadequate entities. $^{15}$

Walter Benjamin introduced what is probably the greatest disturbance in the dependency of the translated text on an original. Benjamin sees in translation something more than the creation of equivalences, and he points at the difference between the burden of literal meaning and the 
intention of a text to reexamine the process of translation. ${ }^{16}$ Preserving literal meaning, although to an extent necessary in translation processes, is not the real task of the translator. Translators have to grapple with the intention of a text and can never remain tied to its literal meaning if they want to live up to their task. Benjamin writes, meaning is fully realized in accord with "its poetic significance for the original." 17 That relation between an original text and its place in its own language, both structurally and culturally, confers a piece of work its meaningfulness, its intention. Through the process of translation the purpose is to discover and establish a similar intention in the resulting text by attending to how "what is meant is bound to the way of meaning [the intention] of the individual word." 18 The translator is not looking for equivalence but for an analogous play of words, meanings, and intentions. She is working at the level of the poetic function of language as much as she has to deal with the more mechanical replacement of words to solve the first order problem of denotation. For Benjamin, a translator that wants to reach the mode of intention of a text needs to engage with "the unfathomable, the mysterious, [and] the "poetic"" dimensions of meaning. ${ }^{19}$

But the search for that poetic dimension does not always yield a text worthy of translation. Poetic translations, as opposed to merely informational ones, are necessary when a piece of work has reached such fame ${ }^{20}$ that it spawns a "fruitfulness ... [and] expansion" of such pieces shows a dual purpose. On the one hand, it grants the original an afterlife. On the other hand, it invokes a series of new semiotic relations that are more than mere replications of the original. This translation establishes new relations in the new [End Page 33] language; it also renews and reinvents the original. We can speak about an "original" only thanks to the new text that a translation retrospectively produces. When a text is translated, the new version turns back toward the chronologically prior text and converts it into something new. This shows how the process of translation works backwards in time, in as much as it can create a preexisting text anew, transform it into something different, and make it count as an original. In this vein, it seems possible to say that the expansion of human rights institutions, discourses, and initiatives is, in a way, a nurtured afterlife to an original text that has been translated into organizations, courts, lawyerly traditions, and ultimately into two words - human rights - that capture and impose a peculiar conception of the human and her most fundamental core. From this point of view, a translation of the human right to water is much more than the mere replacement of words from one language to another. It is a poetic expansion of its semiotic, political, and material effects. $^{22}$

To unleash the analytic potential of this type of translation we have to attend to the new poetic connections of socio-legal discourse and material organization that the translation of human rights entails. ${ }^{23}$ We need to map the effects of translation in "real life discourse," that is, in culture. ${ }^{24}$ For Michael Silverstein, any translation of meaning, to be successful, needs to place the translated text not only in relation to the grammatical and lexicographic structures of a language but also needs to attend to its potential contextual location as it would occur in [End Page 34] culture. ${ }^{25}$ In other words, a human right that is expressed through percentages is an instance of translation in real life discourse. The relationships between nongovernmental organizations (NGOs) and regulators in Costa Rica provide an example of such translation in real life discourse. Silverstein explains the process of translating meaning in real life discourse as 
a process of reorganizing the source semiotic organization ... by target expressions-in-co(n)text of another language presented through perhaps semiotically diverse modalities differently organized. ${ }^{26}$

In this definition, "source" refers to the original or chronologically prior language or text, and "target" refers to the new language or domain into which the object of translation is introduced. The key here is the open space for transformation, augmentation, and expansion that the target modalities offer and, in fact, require if the translation is to perform something more than a denotational function. In other words, if the translation taps into the poetic-something necessary for the complex transmission of meaning - the translator needs to reorganize the poetic significance of a text according to the new language's semiotic relations. In grasping what in the above definition appears as "diverse modalities differently organized," we are precisely identifying those new relations established contextually in the new language or domain. But, so far I have referred to context from a purely semiotic perspective and have not considered how meaning is placed in broader ideologies, not only of language but of the very possibility of translation as a social phenomenon in a world rife with history and politics. Let me scale up to consider the historicity of translation as a political project of contextualization with concrete legal and material effects.

Elizabeth Povinelli reminds us that despite our awareness of the impossibility of transparent translations across incommensurable fields, the foundational liberal value of charity continues to herald desires for translation as a means to create harmony and understanding between [End Page 35] asymmetric and irreconcilable political actors. ${ }^{27}$ If that liberal impetus is further historicized, we find that the problem of translation is, ultimately, a problem of the very existence of liberal modernity. ${ }^{28}$ The fundamental unit of the modern international order, despite claims to the contrary, continues to be the nation-state. As geopolitical units, nation-states stand in equality to other units - other nation-states - belonging to the same species. ${ }^{29}$ Naoki Sakai shows how this cofiguration of nations with their own ethnic and language identities is the conditio sine qua non of the modern international political and legal regime in which language is used to differentiate identities, cultures, and meanings. ${ }^{30}$ This liberal regime desires harmony and understanding to produce a cosmopolitan co-figuration of global order. Sakai's historicizing of this regime reminds us how the problematic nature of translation, with its possibilities and impossibilities, depends on how this harmonious configuration officializes certain languages at the expense of others that become dialects, unofficial, or regional languages. ${ }^{31}$ Within these asymmetries, translation is expected to momentarily cut across hierarchies and culture to make global circulations and communication possible. ${ }^{32}$ Anthropologists and other cultural brokers, including lawyers, regulators, and NGOs, are active participants in these landscapes and find themselves involved in processes of translation that simultaneously exacerbate and erase difference and hierarchy.

Yet, these hierarchies do not make regulatory translations unidirectional processes. Preexisting and asymmetric differences in language, meaning, or register are not stabilized through the unidirectional movement of a semantic unit from language $\mathrm{A}$ into language $\mathrm{B}$ or from the international to the national legal regime. [End Page 36] Whether it is the translation of an international law textbook first written in English into Chinese, Italian, and Spanish during the nineteenth century, ${ }^{33}$ the translocation of feminist political programs in Eastern Europe by way of U.S. research and aid institutions at the end of the twentieth century, ${ }^{34}$ or the assertion of 
moral normativities through the dubbing of foreign films in Indonesia at the outset of the twentyfirst century, ${ }^{35}$ the multidirectionality of translation challenges the idea that one can merely focus on endpoints. ${ }^{36}$ A point of arrival in the new domain/language of a translated entity is only partial to the translation since, to refer back to Benjamin, the original is always created anew through the process of translation. Translation retrospectively bestows the original with that quality; the point of arrival creates the point of departure. As a multidirectional phenomenon, translation mediates the movement of ideas and meanings while allowing segments of discourse to be recontextualized and put into conversation, and even competition, with other ideas, texts, and voices. ${ }^{37}$ In that multidirectional circulation of meanings and texts, numbers are ubiquitous. Relying on the peculiar role that modernity assigns them for the creation of knowledge, imagination of progress, and adjudication of rights, numbers play specific roles in the real life, as Silvestein would have it, discourse of human rights. As semantic resources, numbers actively participate in hierarchies of officialization and dialectization of forms of knowing. As quantification tools and privileged semiotic resources of modernity, they constitute a specific genre of communication with distinct capabilities and politics. ${ }^{38}$ [End Page 37]

\section{Translation Across Genres of Communication}

I have referred to the poetic level of translation by looking at the semiotic possibilities of language and at the historic context in which translation emerges as a necessity. I have not yet referred to translation across genres of communication. By genres of communication, I refer to languages and the material forms they take through different meaning-conveying artifacts. As technologies to create and circulate meaning, genres of communication grant the poetic level of translation with different horizons of possibility. For instance, when stenographers were brought into Japanese law-making bodies during the late nineteenth century, their translation work evinced remarkable effects. Miyako Inoue shows how the translation of voice into letter unleashed a series of radical inventions. ${ }^{39}$ First, the stenographic record translated voice into a regime of accountability, evidence, and verification of political speech characteristic of western modernity. Second, this new genre granted the emergence of three new entities: a speaking political subject, a political and legal record, and a subject to consume and verify those records. Translating voice into the written genre was the condition of possibility for the more radical effect of creating new subjects and new politics. ${ }^{40}$ Following Inoue's line of inquiry, I ask what happens when a legal construct, such as the human right to water, is translated through a quantified genre of communication?

It has been argued that the increasing popularity of numeric devices as a means to politicize or depoliticize questions of rights and justice coincides with a temporal shift into a neoliberal era that promotes a monolingualism that "abolishes the possibility of alternative worlds for it abolishes the distinctions and differences that mark these [neoliberal] practices ... and the alternative socialities they enact." 41 Couze Venn sees this monolingualism as a triumph of market and corporate logics as dominant parameters for understanding social life. ${ }^{42}$ Historically, market logics and numeric forms of communication have been closely associated, and, for that reason, numeration in our neoliberal societies is often read as marketization. But, efforts to shift social and natural worlds into quantified genres of communication have also existed [End Page 38] through science and its aspiration for monolingual objectivity. ${ }^{43}$ Numbers have been 
historically used to generate an aura of objectivity for phenomena that are taken as real only after their very counting has occurred. ${ }^{44}$ These phenomena are then marked by the technical and scientific aura that numbers carry with them. Supported throughout the nineteenth and twentieth centuries by the international mushrooming of national centers of official calculation, efforts to quantify social life have taken variegated forms and have experienced long histories beyond the neoliberal times we live in. ${ }^{45}$ Quantified facts have created populations, organized tax collection structures, allowed the management of life and death, and produced the normal and the typical. ${ }^{46}$ They have helped corporate logics expand and scientific prestige permeate through a myriad of social spaces that could have privileged other forms of knowing and feeling.

While considering that their effects on society are historically specific, it is safe to say that today numbers draw their political and popularized power from widespread desires for openness, transparency, and visibility, even at the expense of nuanced and more precise accounts of the world. ${ }^{47}$ Numbers are used as if they were clean accounts of the world with the ability to purport unambiguous, unbiased, and neutral knowledge. Not by chance do human rights actors think about numbers when they imagine better targets of intervention. Paradoxically, though, it is also well known that numbers do not have intrinsic truth-telling capacities but, as any other semiotic resource, can be used to produce all sorts of stories. Nevertheless, their place as guarantors of neutrality, knowledge, and objectivity in society continues to be cultivated across a growing number of social locations. From that powerful and [End Page 39] contradictory position, numbers often function as a genre of communication in which the real life discourse of regulation, politics, and law is negotiated and constantly translated. ${ }^{48}$ To query the effects of translating human rights through this genre of communication I now move to two examples and trace the poetic purpose, the intentio, of translation to illustrate the complex and animated afterlives they bestow to the U.N. resolutions through which human rights are formally adopted.

\section{Percentages as Echoes of Status and Contract}

Between 2006 and 2009, a coalition of NGOs in Costa Rica worked to develop a system of indicators to measure their own knowledge about the human right to water, its meanings, and the tools available to promote its implementation. ${ }^{49}$ Working in a country where more than $90 \%$ of the population has access to improved sources of water, ${ }^{50}$ the indicator system was not designed to measure access to water per se. It was intended to gauge the degree to which the notion of a human right to water was a vibrant and lively idea amongst a group of organizations involved in different forms of water activism.

Funded by a Spanish aid agency, the broader context of the project included Spain's insistence upon measuring the impact that its aid was having in the country, particularly by quantifying the relevance of the human right to water as a political object of concern. From the Costa [End Page 40] Rican NGOs' perspective, this project was a strategic opportunity to broaden political discussions of water beyond the question of access for the poor. They used the project to draw attention to two issues. First, they hoped to quantify the labor they put into managing water infrastructures and securing access for a large part of the Costa Rican population via community aqueducts. Second, the NGOs wanted to identify the necessary skills that would enable them to increase their impact on broader national political discussions about water as a public good. The 
numbers the NGOs wanted to produce would both valorize their labor and quantify their lacks; they would create a history and invent a future of increased skills and improved opportunities for political intervention.

As part of the project, the NGOs negotiated that, instead of hiring an outside consultant, they would use their own know-how to construct the numeric indicators necessary to evaluate their project. After careful and systematic preparation, the participating NGOs agreed on the basic steps their number-creating enterprise would follow. First, they would quantify participant's understandings of water issues before and after a series of training events. The training sessions were designed to increase participants' knowledge about gender issues, Costa Rican water law, the meaning of human rights, the concept of integrated water management, and tools to improve the organizational efficiency and transparency of participating NGOs. Second, they would compare the percentage difference between participants" "knowledge, attitudes and practices" before and after the training events. Finally, they would interpret the resulting numbers as indices: first, of the impact the training project had had on participants and, second, of the areas in need of future investment, training, and monitoring. These somewhat characterless numbers would translate simplified notions of human rights into a sense of self that was otherwise difficult to articulate. ${ }^{51}$ In this translation, two registers intersected: the philosophy of human rights, and the density and multiplicity of everyday experiences of rights and obligations.

This combination allowed participants to articulate not only the efficacy of the training sessions but, more importantly, their own sense of collective being; a new type of subject that could not be reduced to an individual rights bearer. The participants, who ranged from small landholders in the rural areas to technical personnel with graduate-level educations, were invested in devising an indicator system that did [End Page 41] not stagnate their collective efforts. They wanted a numeric system that could translate their own complex and unfolding sense of who they were when working for water issues. The participants did not want to find themselves at the end of the project with a static picture of themselves as either farmers, leaders of women's organizations, or executive directors of transnational NGOs. Rather, they aspired to a more sophisticated rendering of their experience as human rights activists. They wanted to translate their ongoing and changing sense of obligation toward each other as more than an aggregation of individual subjects with rights. This enhanced sense of self had to be captured in its unfolding temporality and not merely as a collection of units holding abstract rights. The subject of the human right to water needed to be measured as a network of responsibilities, skills, and obligations in continuous change.

The translation work that percentages perform in this context helps shift the notion of the subject that international human rights regimes presuppose. It moves from a stable, predetermined individual unit to an understanding of the self as the temporality of semiosis. ${ }^{52}$ In this view, the self is constituted by the events that she experiences through time: when I joined a group, when I was married, when I acquired a political view, or when I left a civic group. ${ }^{53}$ In this notion of subjectivity, a legal philosophy of universal rights is the source in need of translation. The temporality of semiosis, the unfolding social being of subjects, is the target language through which the afterlife of human rights is augmented. While human rights are adjudicated on the basis of the status of a person as a member of humanity, that status is never enough for the active and material assertion of those rights. The real enjoyment of these universal rights takes place in 
the lives of persons through the flow of time, and amidst the changing relations of which they are a part. This subject, existing in the flow of time and through relations to others, is the person that comes into existence with the shift from status to contract in the philosophy of rights. ${ }^{54}$

When rights are adjudicated on the basis of status, the "when" that punctuates the history, and the possibility of change, of a person's life is dissolved. In the regime of status, there is no "when." Subjects are always already given entities with rights under the ontological mantle of nature, law and/or god's supra temporal being. When rights are [End Page 42] adjudicated on the basis of man-made agreements or contracts, things change. Subjects acquire a history and a fate. ${ }^{55}$ Theoretically, they can now manage and alter their rights on the basis of the contract that establishes their socio-legal presence. The regime of contract inaugurates the temporality of semiosis with the contract that the subject enters into. From there, existence becomes a series of political and legal moments, "when" rights, obligations, and responsibilities are enjoyed, modified, or erased. In human rights regimes we find this distinction collapses as universal rights simultaneously activate status and contract. It is in the realm of contract that we find the specific arrangements that societies make to assert the inalienable human rights of citizens. It is in the realm of status, the abstract notion of a global humanity, that those rights find their legitimacy and authority. For the NGOs I worked with, explaining that unfolding dual self with words is extremely difficult. But the act of measuring their own knowledge about their inalienable rights became an equivalent to the moment of contract, insofar as it punctuated the flow of being by offering a genre of communication through which obligations, responsibilities, and skills could be named, not merely as snapshots of their status as humans, but as malleable and changing specific relations. Percentages, with their capabilities to measure and index transformation, communicated that dynamic and changing system of skills, knowledge, and responsibility that holds participants in this project together. The percentages the NGOs calculate translate a succinct human rights text into a communicable self in constant transformation of its material and political relations.

To better grasp this temporal being, consider one seemingly inconsequential exchange between one of the project organizers and members of the participating NGOs. During a meeting one of the leaders was reviewing the percentages they had produced so far and presenting them to an audience of project participants. In her presentation she showed how only $80 \%$ of the participating organizations understood the economic implications of legally declaring water a public good. She then displayed a pie graph with $80 \%$ of its volume colored in a light purple and $20 \%$ in a darker burgundy color. The ensuing exchange revolved around what activities would be necessary to turn that $80 \%$ into $100 \%$, ending with the selection of specific NGO members that would be responsible for carrying out these activities. Here, an apparently simple remark anchored the necessity of subsequent actions by project participants to achieve full knowledge [End Page 43] about the implications of a human right, which they believed would lead to a better enjoyment of their inalienable status as humans.

In this case, percentages quantified, translated, and reorganized two types of relations. The first relationship type is lateral. The figures, put side by side, articulated the domains that participants in the project selected as areas of knowledge production and political action necessary to make the human right to water a lively social fact. Those domains included water management, gender, lobbying skills, tools for economic valuation of water resources, and accounting and 
administrative skills. The second type of relation that percentages translated into numbers is temporal. By establishing that, for example, $80 \%$ of the participating organizations understood how to measure the economic value of water, an implicit impetus toward a $100 \%$ target - toward full knowledge and full being — was created.

This is the future that the percentage inaugurates, the yet-to-come temporal domain of this collective self as it is brought into being by the organization's work. This is a quantified self with an impetus toward change in the continuity of time and through better targets. Rather than producing a decontextualized universal account of the subject of human rights, the very synthetic power of the percentage communicates intention and responsibility. It helps exteriorize and notate the system of past relations and future commitments that these organizations understand themselves to hold when working on water related issues. Evidently, these symbols do not capture the whole of their being, in part because that fixed whole is an artifact of a fixed ontology that does not exist, but also because they are all more than water activists. Their selves are always in excess to what this, or any, system of numeration can represent. These symbols establish new relations with a future trajectory that promises the disappearance of the chronologically prior situation. They turn part of the NGO's action into complex targets to project their responsibility and increase each other's knowledge and skills in the future.

The moment of translation I have isolated with this example is the moment of translation of the abstract universal human right based on status into a dynamic and intersubjective system of "contractual" unfolding responsibilities. The complexity of this sense of self requires semantic forms that permit its externalization and permanence through the passage of time. NGOs use percentages to shift genres of communication, externalize that system of obligation, and translate it into a temporally unfolding process that punctuates the exercise of rights. This poetic translation augments the figure of the universal right based on status by adding the questions of knowledge and skills as the new realm on which the existence of rights can be gauged over the [End Page 44] passage of time. While this example emphasizes the person and the qualitative relations through which one makes the abstract promise of a human right into a concrete set of events in time, the next example shows how percentages translate human rights into new economic domains, while protecting the part-whole relation between the person and the collective that is characteristic of liberalism and, by extension, of human right philosophies.

\section{Percentages as Translators of Part-Whole Relations}

To facilitate the implementation of the human right to water, the United Nations Development Program (UNDP) has produced a series of specific guidelines and concrete targets to interpret its scope. I am particularly interested in how the UNDP explains "affordability." With unexpected specificity, the UNDP states that for water to be affordable, households should not spend more than $3 \%$ of their income on water and sanitation services. ${ }^{56}$ This figure travels across international meetings, ministerial cubicles, and NGO reports. In its quiet dislocations, it connects the purported universality of a human right with the specificity of local households in a place like Costa Rica. Setting aside the actual magnitude of the 3\% directive and focusing on the notion of the percentage itself, we can see how, by connecting wholes (income) and parts (water expenses), the UNDP guideline establishes normative relations that parallel the very fundamental 
understanding of the links between individuals and the nation in liberalism. In liberal democracies, the part-whole relation explains the connection between the subject and the sovereign, the citizen and the nation. ${ }^{57}$ In principle, each individual person is a unit that, in the company of other units of equal importance, adds up to the collective national body. The graphic representation of the Hobbesian sovereign captures beautifully this relation: a series of small persons, grouped closely against each other, giving the sovereign the very matter out of which it is made. Although notions of personhood have not remained historically fixed and at points seem to be multiplying - consider, for instance, discussions about whether a fetus or animals are entitled to rights $^{58}$ — the unitary person within the body [End Page 45] of the sovereign continues to be taken for granted as a receptacle of political, cultural, and economic rights.

Once liberalism imagines itself as explicitly universal and becomes a globalizing historical project with institutions like human rights, a new whole, humanity, envelops individuals and creates a superior, all encompassing entity from which personal rights are endowed. This new whole allows for the emergence of a parallel whole to the sovereign. That new whole is humanity, and it makes possible the creation of the individual holder of human rights as its part. But the endowment of rights on the basis of a shared humanity is not a seamless or transparent process. With the 3\% guideline, for example, the UNDP moves our attention from abstract renderings of universal principles to a specific and very concrete domain of social life: economic exchange. This shift bypasses the abstract figure of the generic rights-holding person to set our gaze on accounts, expenses, and prices produced through a series of technical and calculative practices that we commonly do not associate with the realm of human rights. Those calculative practices are, I argue, part of the rich social locations through which the philosophical and liberal association between humanity and the subject is given concrete content.

The need to follow UNDP's 3\% guideline requires the translation of somewhat unproblematic ideas of persons who are part of a larger humanity into uncharted territories where their takenfor-granted entitlements are not enough to assert that the person and the household will only pay $3 \%$ of income for water. In this new life, what for classical liberalism was a stable part-whole relation between the subject and the sovereign is now projected as the relation between a person and humanity as a whole. Not only that, but this part-whole relation requires a series of distinct and mundane relations necessary for the active enjoyment of the universal rights that capture the membership of the person in the whole of humanity. One of those parallel part-whole relations exists between total household expenses and water expense (See Figure 1). In more concrete terms, regulators turn a monthly expense, the payment to a water utility, into the concrete part through which the implementation of a universal human right involves a new multiplicity of actors and institutions. Importantly, for this translation process the normative question of whether $3 \%$ is an appropriate proportion of the income to secure affordability, as opposed to $2 \%$ or 4\%, is not my focus here. Rather, this example highlights how regulators [End Page 46] draw on seemingly structural part-whole relations to translate their share of responsibility for the practical adjudication of human rights. ${ }^{59}$ 
Figure 1. Parallel Whole/Part Relations

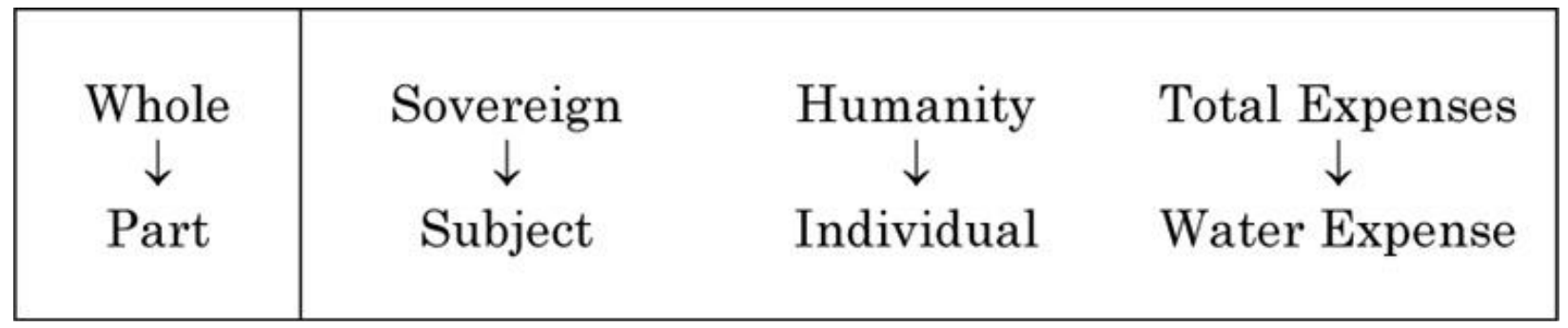

According to the National Institute of Statistics and Census of Costa Rica, an average household spends between $1 \%$ and $2 \%$ of its monthly income to pay for water. ${ }^{60}$ The prices paid by households are set by Costa Rica's public services regulatory agency for whom the question of affordability has long been a concern. To define affordability for the resolutions that make its technical decisions public, the agency has at its disposal a series of hybrid legal-economic instruments that reflect both national political programs and globalized economic ideologies. To think more concretely about those resolutions, I now turn to Sofia, an expert who works for Costa Rica's public services regulatory agency (Autoridad Reguladora de los Servicios Publicos), known as ARESEP for its name in Spanish.

ARESEP is the agency that sets the price of all legally defined public services in Costa Rica, including water and sewage, public transportation, and oil provision. Through her job in the agency, Sofia is committed to producing sound numerical logics that make water participate in the country's socioeconomic life without succumbing to supply and demand abstractions and, most of all, so that water continues to be a human right. Her reliance on economic methodologies, which are grounded in neoclassical schools of economic thought, coexists with recurrent irruptions by court rulings and demands from NGOs to respect and implement the human right to water. While these demands introduce pause in the confidence that she and her colleagues have in their economic tools, they have also infiltrated into some of the regulators' own thinking about the importance of their work. At times, [End Page 47] the human rights topic leads regulators to heated discussions about the role of the state in society; at other times, it results in stereotypical characterizations about the kind of public servant each of them is. Newer cadres, who prefer to concentrate on maximizing the economic and managerial efficiency of the public entities they regulate, clash with those who wholeheartedly believe in human rights and are mocked as "old school" regulators. While the newer personnel concede the relevance of human rights, they do not spend much time experimenting with how that idea is incorporated into their regulatory methodologies. Yet, for both older and newer cadres, the UNDP's 3\% figure works as a translator of the abstract notion of human rights into the economic realm and into the specifics of the spending patterns of Costa Rican households. The concrete point at which regulators intervene in the implementation of the UNDP's guideline is when they set the prices that utilities will charge households for providing water for human consumption. The specific tools employed by regulators to set utility prices include inflation rates, consumer price indices, and household consumption patterns, all of which are somewhat surprising numeric forms to translate human rights.

In 2007, Sofia was in charge of analyzing the viability of a water price increase petitioned for by the country's largest water utility. Her job requires her to respond to this type of routine petition 
by way of a series of technical resolutions that are crafted by ARESEP personnel and signed by the head of the technical department or the head of the regulatory agency. These short texts have very regimented formats that connect utility expenditures, household budgets, notions of fairness, and rights in unexpected ways. I began to discover those connections by tracing the technical backing of those resolutions. When I first met Sofia at a public hearing, she was presenting a fifteen-minute technical assessment of the solicited price increase. ${ }^{61}$ Between arguments of debt repayment, user satisfaction, and balanced budgets, she said that a price increase of $80 \%$, as requested by the utility, was excessive. Although spread across five years, the supporting documents the utility submitted did not justify the increase. Sofia further emphasized that "any change we approve, regardless of economic arguments, has to consider that water is a fundamental human right and should be affordable." This comment was a signal to utilities that the technicality of her final resolution would be tempered by her obligation to implement the human right. [End Page 48]

Later, when I asked her how she translates human rights into prices that are acceptable for utilities, she gave me an answer condensed in a technical concern. She began by walking me through the two-stage analysis ARESEP routinely performs when they receive a price increase petition. First, regulators determine a basic calculation of the price of water by accounting for the costs and expenses utilities incur in their regular operation. Second, regulators consider the best mechanism to periodically update that calculation. For the first stage, they use a price-setting methodology, adopted during the 1960s, that focuses on the costs of service provision and sets strict controls on the generation of any profits. Sofia described this as an "accounting" approach to regulation, as opposed to an "economic" approach that focuses on the efficiency of each utility in the industry. In an accounting approach, if regulators find a justifiable increase in a utility's costs they generally approve some increase in price. If they do not find a justifiable increase in costs, the regulators consider the effect of inflation on the utility's accounts.

In the second phase, regulators focus on the loss of value that capital undergoes due to inflation and use inflation rates as tools to balance their commitment to the UNDP's 3\% target and their concern for the financial wellbeing of utilities. Following international trends in macroeconomic theory and policy, ${ }^{62}$ regulators have settled on inflation as a universal and independent economic instrument that is fair enough to be associated with human rights and concrete enough to help meet the 3\% target. In their view, the inflation figure is universal because it applies to all economic transactions and resources irrespective of the political standing or class location of a person, company, or good. Because inflation is calculated with a methodology that, in theory, does not benefit any sector of the economy, regulators deem this figure an independent and neutral tool.

In Costa Rica, inflation is measured using the consumer price index produced by the National Institute of Statistics and Census (INEC). This index tracks the price variation of a list of goods and services representative of the middle class, urban population of the country. ${ }^{63}$ To [End Page 49] collect the data, every month INEC representatives visit a secret sample of commercial establishments and record the prices of the items in the list. Back in the office, they input the price data into a weighted formula that, after complicated calculations, yields a percentage of change in the basket of prices they monitor. Economic authorities in the country adopt that final percentage as an official measure of inflation. When utilities approach the regulatory agency to 
solicit a price increase without any major projects or investments that augment their expenses, regulators turn to the inflation rate as a measure of how much more money utilities may be entitled to collect. For regulators, the inflation rate is a measure of economic entropy for which it is only fair that utilities be compensated. Citizens, on the other hand, do not experience any similar compensation. In the past twenty years, the minimum wage policies of Costa Rica have never equaled the inflation rate; yet, public service prices are often updated using the inflation measure as a fair compensation for the economic loss utilities have experienced. ${ }^{64}$ Compensation for entropy is naturalized as a right of utilities but not of the working citizens.

The method used by INEC to calculate inflation becomes useful for ARESEP's commitment to $3 \%$ in two ways. First, the data INEC collects informs regulators about the consumption practices of households. Although this is not precisely information about income as UNDP calls for, it draws a statistical picture of all the expenses that households incur. This statistical picture allows them to monitor whether the effects of their resolutions push the proportion of monthly expenses for water up or down within the total monthly spending of households. Second, as noted above, the inflation figure, with its aura of independence and fairness, helps regulators judge whether their decisions abide by the ethical and distributive concerns that human rights index. In the fluidity of everyday regulatory work, the inflation rate functions as a proxy of fairness and as a tool to ensure that Costa Rican households, if only those statistically connected to the calculation of the consumer price index, set aside the right proportion (3\%) of their income for water. For Sofia, considering the struggles between new and old cadres of regulators, translating human rights through numbers is, in fact, a way to repoliticize what are otherwise somewhat mechanical regulatory practices. [End Page 50]

Ultimately, and despite the possible distortions that their use of the inflation rate introduces to the notion of universal human rights, the technical choice regulators make relies on part-whole relations to translate their commitment to universal access into the realm of household economics and consumption patterns. These relations between water and the consumption practices of households expand the original meaning of affordability to encompass inflationary concerns, consumption patterns, and macroeconomic trends. Augmenting the legal existence of human rights that were once localized in international law books, institutions, and courts to now include household budgets, the institutions that calculate the bills that arrive every month to water users provides the human right to water an afterlife that expands its liveliness in real life discourse. Its real life significance is accomplished, in large part, by replicating the part-whole relation that undergirds human rights regimes at the specific level of the water expense and the household budget. Regulators, via percentages, associate new realms of social life under the premise of the ethical maintenance of the part-whole proportionality. In this afterlife, actors who would otherwise see themselves as extraneous to international law are actualizing such rights. Percentages make this translation into new contexts possible, not only because they articulate new semiotic and material fields, but also because they carry over the intention of human rights into the daily work of regulatory institutions. While in principle humanity as a whole and the individual as its part are the units on which relations of liberal belonging depend, in the implementation of the human right to water, those units are replaced by new ones. Water expense (part) and total household expenses (whole) reinscribe the liberal relation of belonging into the sphere of economic exchange. 


\section{Conclusion}

The philosophy of human and civic rights creates the exclusion of an exclusion. ${ }^{65}$ It instantiates the impossibility of excluding any human being from the principle of common humanity on the basis of status. Yet, the affirmative dimension of human rights, their implementation in the world, hinges not on the impossibility to exclude but on the necessity to include in the temporality of social life. To promote the active enjoyment of rights, the question becomes how to augment, multiply, and translate the social life of human rights. In the two examples I have outlined, percentages are used to identify better targets [End Page 51] to do so. Percentages take seemingly narrow definitions coined in U.N. resolutions and translate them into complex webs of signification, responsibility, and proportionality. Pregnant with their peculiar semiotic charge of communicating their own transformation, percentages invoke the temporality of social life and its fluidity. Translation, as a process of augmenting the chronologically prior text by creating it anew, offers new ways to rethink the role that numbers, as a peculiar genre of communication, play in political and legal life. Instead of suggesting that numbers are used to exclude, as arguments against the quantification of rights often do, I have focused on how they can create semiotic, political, and material relations that instantiate what I have referred to as the productive dimension of human rights: the necessity to include.

In these examples, NGOs and regulators happily embraced the positive dimension of human rights discourses. But of course, the generalized principle of the necessity to include becomes murky and complicated in its concrete delineation. In translation, the specific meaning of the human right to water as a set of skills and as the right to affordability become deeply vexed, augmented, and, possibly, partially betrayed. These complexities illustrate how percentages participate in the quest for political recognition and implementation of the human right to water while endowing the original text with new life amidst pie graphs, indicator systems, household budgets, and inflation rates. Percentages are able to communicate the simultaneous reliance on status and contract of human rights in their unfolding temporality. They also allow the proliferation of parallel part-whole relations through the very technicalities of price calculations. Translation stimulates the creation of new and unanticipated relations that are available for our understanding if, as Benjamin suggests, we pay attention to the poetic dimension of meaning. Percentages work as poetic targets for human rights interventions whose meaning always exceeds literality.

Efforts, aspirations, and technical knowledge are all mobilized into active and generative processes of multidirectional and polysemic translation for which value lies not in the preservation of meaning but in the inventiveness and productivity with which universal claims are recontextualized. I have shown the diverse and complicated operations necessary for translating human rights through ubiquitous numeric devices to which scholars might have become desensitized, given how often they are taken for granted. Ultimately, my objective has been to highlight the tremendous effort required to provide human rights with an active life and the unexpected locales where that effort is being performed. Translation, as a poetic process of meaning augmentation, [End Page 52] offers a productive way to think about how different genres of communication are suited to expand the social and material life of human rights. It is there, in the nonmonumental work of everyday knowledge forms, that we often find crucial insights to understand, if not transform, the world that surrounds us. [End Page 53] 
${ }^{1}$ See International Decade for Action, "Water for Life", 2005-2015, G.A. Res. 58/217, U.N. Doc. A/RES/58/217 (Dec. 23, 2003).

${ }^{2}$ Catarina de Albuquerque, Water and Sanitation are Human Rights: Why Does it Matter?, in International Law and Freshwater 48, 51-52 (Laurence Boisson de Chazournes et al. eds., 2013).

${ }^{3}$ United Nations, Human Right to Water, International Decade for Action 'Water for Life ' 2005-2015, http://www.un.org/waterforlifedecade/human_right_to_water.shtml (last updated Mar. 11, 2014).

${ }^{4}$ See generally Galit A. Sarfaty, Values in Translation : Human Rights and the Culture of the World Bank (2012); Deborah A. Stone, Policy Paradox and Political Reason (1988); Sally Engle Merry, Measuring the World: Indicators, Human Rights, and Global Governance, 52 Current Anthropology S83 (2011).

${ }^{5}$ Isabelle Stengers, The Cosmopolitical Proposal, in Making Things Public : Atmospheres of Democracy 994, 994 (Bruno Latour \& Peter Weibel eds., 2005) (internal quotation marks omitted).

${ }^{6}$ De Albuquerque, supra note 2, at 49.

${ }^{7}$ See, e.g., Sally Engle Merry, Transnational Human Rights and Local Activism: Mapping the Middle, 108 Am . Anthropologist 38 (2006).

${ }^{8}$ See, e.g., Ebru Kayaalp, Torn in Translation: An Ethnographic Study of Regulatory Decision-making in Turkey, 6 Reg. \& Governance 225 (2012).

${ }^{9}$ See, e.g., Nicoleta Medrea \& Carmen Caraiman, The Problem of Legal Romanian-English/English-Romanian Dictionaries and Glossaries and Legal Translations, 14 Jurid . Current 269 (2011).

${ }^{10}$ See, e.g., Daphna Golan \& Zvika Orr, Translating Human Rights of the "Enemy": The Case of Israeli NGOs Defending Palestinian Rights, 46 Law and Soc 'y Rev . 781 (2012).

${ }^{11}$ See generally Laura A. Foster, Critical Cultural Translation: A Socio-Legal Framework for Regulatory Orders, 21 Ind . J. Global Legal Stud . 79 (2014) (examining a similar question by reference to science and technology studies and feminist theory).

${ }^{12}$ As part of the conceptual apparatus of Actor Network Theory (ANT), translation has been examined as a process for recruiting allies in the strengthening and proliferation of human-nonhuman networks. See generally Ziya Umut Türem, Competition Law Reform in Turkey: Actors, Networks, Translations, 21 Ind . J. Global Legal . Stud . 159 (2014) (applying this approach, originally developed by Bruno Latour and Michel Callon). In this paper I examine another theoretical tradition of translation that is grounded in linguistic anthropology and cultural studies.

${ }^{13}$ See Tim Choy, Ecologies of Comparison : an Ethnography of Endangerment in Hong Kong 94 (2011); Naoki Sakai, Translation, 23 Theory Culture \& Soc 'y 71, 71 (2006).

${ }^{14}$ Tom Boellstorff, Dubbing Culture: Indonesian Gay and Lesbi Subjectivities and Ethnography in an Already Globalized World, 30 Am . Ethnologist 225, 236 (2003).

${ }^{15}$ See Elif Babul, Smells Like Translation: Pedagogies of Human Rights and Transnational Standardization in Turkey 2 (Apr. 12, 2011) (unpublished manuscript, on file with author) (presented at Socio-Legal Studies Association Annual Conference 2011).

${ }^{16}$ Walter Benjamin, The Task of the Translator, in 1 Selected Writings 253, 259 (Marcus Bullock \& Michael W. Jennings eds., 1996).

${ }^{17} I d$.

${ }^{18} I d$. at $259-60$.

${ }^{19} I d$. at 253.

${ }^{20}$ See id. at 255.

${ }^{21}$ Eve Tavor Bannet, The Scene of Translation: After Jakobson, Benjamin, de Man, and Derrida, 24 New Literary Hist. 577, 582 (1993).

${ }^{22}$ In Benjamin's schema, human rights translated through percentages recreate the intended object by offering it an afterlife through which the differences between languages, their modes of intention, can flourish. The craft of the translator, then, is to grasp the poetics of language, its form and style, to the extent that they cannot be reduced to denotation. In that exercise, almost unwittingly, the translator brings us closer to pure language. Here, pure language 
is not a coherent, mystical whole, but an articulation of fragments that never fully fit with each other. Those fragments make pure language intrinsically fragmentary, always constituted through negative space. See generally Paul de Man, "Conclusions" Walter Benjamin's "The Task of the Translator" Messenger Lecture, Cornell University, March 4, 1983, 69 Yale French Stud . 25 (1985). As Paul de Man notes, pure language is simultaneously an impossibility and the condition of possibility of translation in Benjamin's rendering. In other words, every language consists of relations amongst form and tropes that yield a modality of meaning-making that we aspire to translate, yet at the same time, those differences make it impossible to produce pure meaning since, as a form, pure language is inherently fragmentary, and thus unknowable.

${ }^{23}$ See generally Kregg Hetherington, Regular Soybeans: Translation and Framing in the Ontological Politics of a Coup, 21 Indiana J. Global Legal Stud . 54 (2014) (another rendering of how regulatory turns, rather than simplifying and framing their objects, can in fact multiply the relations and connections that make those objects in the first place).

${ }^{24}$ See Michael Silverstein, Translation, Transduction, Transformation: Skating "Glossando” on Thin Semiotic Ice, in Translating Cultures : Perspectives on Translation and Anthropology 75, 76 (Paula G. Rubel \& Abraham Rosman eds., 2003).

${ }^{25} \mathrm{Id}$. at 81 .

${ }^{26} I d$. at 83 (emphasis added). Silverstein calls this process transduction in an effort to highlight the indexical signification that is at stake in any process of translation. The process of transduction includes the wiggle room that the translator works with when confronting the options she faces in the act of translating. In other words, transduction accounts to something like translation plus indexical signification. See $i d$. at 83-91, for a more complete examination of the concept of transduction.

${ }^{27}$ See Elizabeth A. Povinelli, Economies of Abandonment : Social Belonging and Endurance in Late Liberalism 81 (2011).

${ }^{28}$ See Sakai, supra note 13, at 77.

${ }^{29}$ See generally Charles Taylor, The Politics of Recognition, in Multiculturalism and "The Politics of Recognition" 25 (Amy Gutmann ed., 1992); Shannon Speed, Dangerous Discourses: Human Rights and Multiculturalism in Neoliberal Mexico, 28 Po LAR: Pol .\& Legal Anthropology Rev . 29 (2005), for discussions on multiculturalism and their relation to difference.

${ }^{30}$ See Sakai, supra note 13 , at 75.

${ }^{31}$ See id. at 75-77. Sakai's historicizing move takes the idea of translation across languages as the universal type of translation. This observation needs to be tempered by examining translations across different semantic forms, or as I will show, genres of communication, and evaluating whether that process needs to be described in different terms. This paper is a modest experiment in that direction.

${ }^{32}$ See Talal Asad, The Concept of Cultural Translation in British Social Anthropology, in Writing Culture : The Poetics and Politcs of Ethnography 141, 156-160 (James Clifford \& George E. Marcus eds., 1986).

${ }^{33}$ See Lydia H. Liu, Legislating the Universal: The Circulation of International Law in the Nineteenth Century, in Tokens of Exchange : The Problem of Translation in Global Circulations 127 (Lydia H. Liu ed., 1999).

${ }^{34}$ See Susan Gal, Movements of Feminism: The Circulation of Discourses About Women, in Recognition Struggles and Social Movements 93, 98-99 (Barbara Hobson ed., 2003).

${ }^{35}$ See generally Boellstorff, supra note 14.

${ }^{36}$ See generally Yasmine Chahed, Translations in Regulatory Space: The Arenas of Regulatory Innovation in Accounting Standard Setting, 21 Ind . J. Global Legal Stud . 195 (2014) (another analysis of how multidirectional processes of translation take place in regulatory environments).

${ }^{37}$ See Gal, supra note 34 , at 93.

${ }^{38}$ Some of their celebrated capabilities in modernity include the presumed mobility, stability, and combinability. See Keith Robson, Accounting Numbers as "Inscription": Action at a Distance and the Development of Accounting, 17 Acct . Org . \& Soc 'y 685, 701 (1992). Numerical accounts are believed to be transportable, highly adaptable to new external contexts, and crucially, capable of being arbitrarily combined with other accountings enabling the creation of new entities. In the realm of politics and law, calculative technologies supposedly enable programmatic action, make "still" prescriptions dynamic, see Bruno Latour, Drawing Things Together, in Representation in Scientific Practice 19 (Michael Lynch \& Steve Woolgar eds., MIT Press 1990); Peter Miller, On the Interrelations Between Accounting and the State, 15 Acct . Org . \& Soc 'y 315 (1990); Stone, supra note 4, at 132, and guide the discovery of "better targets" for intervention, as Catarina de Albuquerque notes, see Albuquerque, supra note 2, at 51-52.

${ }^{39}$ See generally Miyako Inoue, Stenography and Ventriloquism in Late Nineteenth Century Japan, 31 Language \& Comm . 181 (2011). 
${ }^{40}$ See Gal, supra note 34 , at 96.

${ }^{41}$ Couze Venn, Translation: Politics and Ethics, 23 Theory Culture \& Soc 'y 82, 82 (2006).

${ }^{42}$ Id. at 82-84.

${ }^{43}$ See generally Steven Shapin \& Simon Schaffer, Leviathan and the Air -Pump : Hobbes, Boyle, and the Experimental Life (Princeton Univ. Press 2011); Helen Verran, Science and an African Logic (2001); Bruno Latour, Scientific Objects and Legal Objectivity, in Law , Anthropology, and the Constitution of the Social 73 (Alain Pottage \& Martha Mundy eds., 2004); Lorraine Daston \& Peter Galison, The Image of Objectivity, 40 Representations 81 (1992).

${ }^{44}$ See Theodore M. Porter, Trust in Numbers : The Pursuit of Objectivity in Science and Public Life 33 (1995).

${ }^{45}$ See generally Bernard S. Cohn, Colonialism and its Forms of Knowledge : The British in India (1996); Mahmoud Ezzamel, Order and Accounting as a Performative Ritual: Evidence from Ancient Egypt, 34 Acct . Org . \& Soc 'y 348 (2009).

${ }^{46}$ See generally Ian Hacking, the Taming of Chance (1990) (U.K.); Georges Canguilhem, the Normal and the Pathological (1989).

47 See Porter, supra note 44, at 78; Andrea Ballestero, The Productivity of Nonreligious Faith: Openness, Pessimism, and Water in Latin America, in Nature, Science, and Religion 169, 188-89 (Catherine M. Tucker ed., 2012); Merry, supra note 4, at S85; Dawn Nafus, Little Big Data: Stops and Starts in Building Numbering Practices with Sensors (May 1, 2013) (unpublished manuscript) (on file with author).

${ }^{48}$ See generally Bruno Latour, Reassembling the Social (2005); Michel Callon, Some Elements of a Sociology of Translation: Domestication of the Scallops and the Fishermen of St Brieuc Bay, in Power , Action and Belief 196 (John Law ed., 1986), for a discussion of translation as a mechanism to enroll allies for a certain position, cause, or project. The intention of this type of translation is to increase the "power" of a proposition until it sediments through its circulation and becomes an assumed response to a controversy. See Latour, supra; Callon, supra; Bruno Latour, The Powers of Association, in Power, Action and Belief 264 (John Law ed., 1986). There is no doubt that this indeed takes place. Numbers are powerful creators of allies. But certainly that is not the only dynamic at play. See Benjamin , supra note 16, for a notion of translation in which numbers translate rights by generating an echo of the original in the new language. Numbers reinvent and transform the human right to water under the possibilities that the new discursive contexts afford. Here, the intention is to re-enact the relations that the "original" depends on for its own existence through a numeric technology, not exclusively to recruit allies for a proposition, although as noted above that might also be at play. See generally Foster, supra note 11 (analyzing the implications of this modality of translation).

${ }^{49}$ See generally Andrea Ballestero, Transparency Short-Circuited: Laughter and Numbers in Costa Rican Water Politics, 35 Po LAR: Pol . \& Legal Anthropology Rev . 223 (2012) (describing in more detail the construction and implementation of this project).

${ }^{50}$ See Caterina de Albuquerque, Rep. of the Independent Expert on the Issue of Human Rights Obligations Related to Access to Safe Drinking Water and Sanitation, at 2, U.N. Doc. A/HRC/12/24/Add.1; HRC, 12th Sess. (June 23, 2009).

${ }^{51}$ See Ballestero, supra note 49, at 236; see generally Andrea Ballestero Salaverry, Expert Attempts: Water, Collectives, Prices and the Law in Costa Rica and Brazil (May 30th, 2010) (unpublished Ph.D. dissertation, University of California, Irvine, on file with author) (exploring the use of numbers as policy tools).

${ }^{52}$ See Paul Kockelman, From Status to Contract Revisited: Value, Temporality, Circulation and Subjectivity, 7 Anthropological Theory 151, 167 (2007).

${ }^{53}$ Id.

${ }^{54}$ See generally Henry Sumner Maine, Ancient Law (Beacon Press 1963) (1861) (proposing that individuals were tightly bound by status, but in modern society individuals are free to make contracts and associations with whomever they choose).

${ }^{55}$ Kockelman, supra note 52, at 168.

${ }^{56}$ United Nations, supra note 3.

57 See, e.g., Celia Lury, Prosthetic Culture 1 (1998); C.B. Mac Pherson, The Political Theory of Possessive Individualism (1962); Marilyn Strathern, The Whole Person and Its Artifacts, 33 Ann . Rev . Anthropology 1 (2004) (discussing how the "whole" person must be represented by its own technology or artifacts).

${ }^{58}$ Although the exact entities that we recognize as a person have historically changed, I am interested here in the formal unit of the person as an enduring unit through which relations of part/whole are described. 
${ }^{59}$ See generally Andrea Ballestero, Prices Against Markets: Designed Payments and the Calculation of Human Rights in Costa Rica (Jan. 28, 2014) (unpublished manuscript, on file with author) (developing and analyzing this example in more detail).

${ }^{60}$ Household Budget Continuous Survey, Instituto Nacional de Estad ística, http://www.ine.es/jaxiBD/tabla.do?per=12\&type=db\&divi=EPF\&idtab=80 (select "044 Other services related to the dwelling (water, waste disposal, sewerage, community costs, etc.)," "Percentage distribution," and "2006"; then follow "Submit selection" hyperlink) (last visited Dec. 14, 2013).

${ }^{61}$ In Costa Rica the state or federations of municipalities own all water utilities. They are all regulated as public entities.

${ }^{62}$ See generally Douglas R. Holmes, Economy of Words, 24 Cultural Anthropology 381 (2009) (examining how an "economy of words" create context for economic phenomena); Federico Neiburg, Inflation: Economists and Economic Cultures in Brazil and Argentina, 48 Comp . Stud . Soc 'y \& Hist . 604 (2006) (outlining the social and cultural history of inflation to explore the relationational dynamics between economic theorists and economic culture)

${ }^{63}$ Despite regulators' confidence in the inflation rate's fair nature, the fact that it is measured using the consumer price index introduces a distortion. This index reflects average urban middle class households' purchasing power and consumption practices and not the experiences of the extremely poor or extremely rich. When the inflation rate is measured through the consumer price index, and when water prices are updated using the inflation rate, affordability is transformed into affordability for the urban middle class and not affordability for the poor, which is the original motivation of the three percent guideline.

${ }^{64}$ By law, twice a year the government is required to pass an executive decree that updates minimum wages for both public and private workers.

${ }^{65}$ See Étienne Balibar, Is a Philosophy of Human Civic Rights Possible? New Reflections on Equaliberty, 103 S. Atlantic Q. 311, 312 (2004). 